\title{
Characteristics of surface layer proteins from two new and native strains of Lactobacillus brevis
}

\author{
Elahe Mobarak Qamsari ${ }^{\mathrm{a}}$, Rouha Kasra Kermanshahi ${ }^{\mathrm{a}, *}$, Mohammad Erfan ${ }^{\mathrm{b}}$, Parinaz Ghadam ${ }^{\mathrm{c}}$, Soroush Sardari ${ }^{\mathrm{d}}$, \\ Neda Eslami ${ }^{\mathrm{e}}$ \\ ${ }^{a}$ Department of Microbiology, Faculty of Biological sciences, Alzahra University, Tehran, Iran \\ ${ }^{\mathrm{b}}$ Department of Pharmaceutics, School of Pharmacy, Shahid Beheshti University of Medical Sciences, Tehran, Iran \\ ${ }^{c}$ Department of Biotechnology, Faculty of Biological sciences, Alzahra University, Tehran, Iran \\ ${ }^{\mathrm{d}}$ Department of Medical Biotechnology, Biotechnology Research Center, Pasteur Institute of Iran, Iran \\ e Department of Pharmaceutics, School of Pharmacy, Lorestan University of Medical Sciences, Khorramabad, Iran
}

\section{A R T I C L E I N F O}

\section{Article history:}

Received 13 August 2016

Received in revised form 6 September 2016

Accepted 26 October 2016

Available online $\mathrm{xxx}$

\section{Keywords:}

Surface layer proteins

Lactobacillus brevis

Secondary structure

Thermal behavior

Monodispersity

Zeta potential

\section{A B S T R A C T}

In this work, some important characteristics of surface layer (S-layer) proteins extracted from two new and native Lactobacillus strains, L.brevis KM3 and L.brevis KM7, were investigated. The presence of S-layer on the external surface of L.brevis KM3 was displayed by thin sectioning and negative staining. SDS-PAGE analysis were shown same dominant protein bands approximately around $48 \mathrm{kDa}$ for both S-layer proteins. Moreover, the S-layer reappeared when $\mathrm{LiCl}$ treated cells were allowed to grow again. Protein secondary structure and thermal behavior were evaluated by using circular dichroism (CD) and differential scanning calorimetry (DSC), respectively. Both S-layer proteins had high content of $\beta$-sheet and low amount of $\alpha$-helix. The thermograms of lyophilized S-layer proteins of L.brevis KM3 and L.brevis $\mathrm{KM} 7$ showed one transition peak at $67.9^{\circ} \mathrm{C}$ and $59.14^{\circ} \mathrm{C}$, respectively. To determine monodispersity of extracted S-layer proteins, dynamic light scattering (DLS) was used. The results indicated that the main population of S-layer molecules in two tested lactobacillus strains were composed of monomer with an expected diameter close to $10 \mathrm{~nm}$. Furthermore, Zeta potential measurements were showed positive potential for both S-layer proteins, as expected. Our results could be used as the basis for biotechnological applications of these two new S-layer proteins.

(C) 2016 Published by Elsevier Ltd.

\section{Introduction}

Surface layers (S-layers) are surface structures with two-dimensional arrays that composed of identical protein or glycoprotein subunits, varying in mass from 40 to $200 \mathrm{kDa}$, and are assembled on the cell surface with regular and porous array with different kinds of symmetries such as oblique (p1, p2), square (p4) or hexagonal (p3, p6) as observed by freeze-etched electron microscopy. Under appropriate conditions monomers can reassemble in solution or on a solid support into S-layer like structures with the authentic symmetry pattern $[1,2]$. Various functions have been suggested for S-layers, such as acting as molecular sieves, determining the shape of the cell, molecular ion traps, protective coats and promoters for surface recognition and cell adhesion [2]. The cell walls of many Bacteria, including many species of the genus Lactobacillus are covered by the crystalline structure of surface layer (S-layer) [3]. Studies have shown that the S-layer is a typical surface structure in several Lactobacillus species, e.g., in L.acidophilus, L. brevis, L. helveticus, L. buchneri, $L$. casei, L. fermentum, L. bulgaricus and L. plantarum $[3,4]$. Probiotic

\footnotetext{
* Corresponding author.

Email addresses: emobarak110@gmail.com (E. Mobarak Qamsari); rkasra@, yahoo.com, rouha.kasra@gmail.com (R. Kasra Kermanshahi); m-erfan@sbmu.ac. ir (M. Erfan); pghadam@alzahra.ac.ir (P. Ghadam); ssardari@hotmail.com (S. Sardari); Nedaeslami77@yahoo.com (N. Eslami)
}

features of Lactobacillus strains can be interesting factor to S-layer of these bacteria [5-7]. Some biochemical properties of Lactobacillus S-layer are unique compared with S-layer of other bacteria, for example in their smaller size $(25-71 \mathrm{kDa})$ and high predicted $\mathrm{pI}$ value (9.4-10.4). The lattice symmetry of oblique or hexagonal have been seen in S-layer proteins of Lactobacillus [8]. Due to their self-assembly ability and the highly ordered, regular structure down to the nanometer scale, S-layers were demonstrated to possess a great potential in (nano)biotechnology, biomedicine, biomimetics and synthetic biology. Increasing knowledge about structure, chemistry, assembly and genetics of S-layers can assembly be effective for their potential application in future.

In the present study, S-layer proteins from two new and native strains of lactobacilli including L.brevis KM3 and L.brevis KM7 were investigated. In previous study, these two strains have been identified by using $16 \mathrm{~S}$ rDNA primers and demonstrated maximum similarity with the 16S rRNA sequence of Lactobacillus brevis spp. Also, they have been characterized as putative probiotic strains [9]. Analysis of the cell surface topography using TEM technique was confirmed the presence of S-layer onto cell wall of L.brevis KM3. Extraction procedures and re-formation of the S-layer on intact cells after first extraction are described. Also, the secondary structure composition, thermal behavior and zeta potential of S-layer proteins were determined. Biochemical features of S-layers designated that they may offer several advantages for different biotechnological applications. 


\section{Material and methods}

\subsection{Electron microscopy}

The presence of S-layer on selected isolates was confirmed by analysis of the cell surface topography using electron microscopy. One of the two strains (KM3) was selected and prepared for transmission electron microscopy (TEM) imaging.

For thin sections, cells were fixed in $2.5 \%$ phosphate-buffered glutaraldehyde for $1.5 \mathrm{~h}$ at room temperature. Fixed cells were washed three times with phosphate buffer. The samples were post-fixed with $1 \%$ phosphate-buffered osmium tetroxide for $1 \mathrm{~h}$ at room temperature and dehydrated in acetone for $2 \mathrm{~h}$. The samples were then embedded by three successive incubations in Araldite. After polymerization of the resin $\left(60^{\circ} \mathrm{C}, 48 \mathrm{~h}\right)$, ultrathin sections were cut with a LEICA UCT ultramicrotome. Ultrathin sections (thickness, 30-50 nm) stained with aqueous uranyl-acetate and lead citrate was examined by transmission electron microscopy (EM LEO906; zeiss, Germany; 80 kV). For precise investigation of surface layer protein, negative staining was performed. Samples (dialyzed extract of S-layer proteins obtained after treatment by guanidine hydrochloride) were negatively stained by treating the grids with a drop of uranyl acetate and observed transmission electron microscopy $[10,11]$.

\subsection{SDS-PAGE analysis}

SDS-PAGE was done to determine the molecular weight of S-layer proteins. Total cell proteins were extracted by sodium dodecyl sulphate (SDS) solution. The lactobacilli cells were harvested by centrifugation $\left(5000 \times \mathrm{g}, 10 \mathrm{~min}, 4^{\circ} \mathrm{C}\right)$, washed twice with distilled water. The cells were resuspended in $1 \%$ of SDS solution and boiled for $10 \mathrm{~min}$ in a boiling water bath. Then the samples were centrifuged $\left(9000 \times g, 15 \mathrm{~min}, 4^{\circ} \mathrm{C}\right)$, and $40 \mu \mathrm{l}$ of the supernatant was mixed with $10 \mu \mathrm{l}$ of $5 \times$ loading buffer, boiled for $5 \mathrm{~min}$ and analyzed by sodium dodecyl sulphate polyacrylamide gelelectrophoresis (SDS-PAGE) using $12 \%$ polyacrylamide gels. Twenty microlitres $(20 \mu 1)$ of each sample were loaded in each well of the gel. By staining the gels with Comassie brilliant blue, protein bands were made visible $[12,13]$.

For extraction of S-layer protein of selected isolates, the bacteria were harvested at the end of log phase (with optical density of 0.7 at $695 \mathrm{~nm})$ by centrifugation $\left(15000 \times \mathrm{g}, 15 \mathrm{~min}\right.$ at $\left.4{ }^{\circ} \mathrm{C}\right)$ and washed twice with chilled distilled water. The harvested cell pellets were treated with $4 \mathrm{M}$ guanidine hydrochloride (GuHCL) (Merck, Germany). Ten-fifteen $\mathrm{ml}$ of $4 \mathrm{M} \mathrm{GuHCL}$ was added to $1 \mathrm{~g}$ of harvested cell pellets and incubated for $1 \mathrm{~h}$ at $37^{\circ} \mathrm{C}$. The extracted S-layer protein was collected by centrifugation $\left(18000 \times g, 15 \mathrm{~min}, 4^{\circ} \mathrm{C}\right)$. The supernatant containing the S-layer protein was dialyzed over night at $4{ }^{\circ} \mathrm{C}$ against distilled water. Then the surface layers were lyophilized (Christ Alpha 1-2 LD plus) and stored at $-20{ }^{\circ} \mathrm{C}$. Dialyzed protein solutions were suspended in sample buffer for further analysis by SDS-PAGE. In all cases, SDS-PAGE was performed by the method of Laemmli $[14,15]$. During dialysis of the GuHCL crude extract against distilled water at $4{ }^{\circ} \mathrm{C}$, a white precipitate appeared which could be recovered by centrifugation $\left(18000 \times g, 15 \mathrm{~min}, 4^{\circ} \mathrm{C}\right)$. For SDS-PAGE analysis, also this white pellet was resuspended in $1 \%$ of SDS solution and boiled for $10 \mathrm{~min}$ in a boiling water bath. Then, it was mixed with $10 \mu \mathrm{l}$ of $5 \times$ loading buffer, boiled for $5 \mathrm{~min}$ and analyzed by SDS-PAGE [16].

\subsection{S-layer re-formation after first extraction with $\mathrm{LiCl}$}

Cells from exponential phase were harvested and washed twice with distilled water. Ten-fifteen $\mathrm{mg}$ of the moist pellet were suspended per $\mathrm{ml}$ of $5 \mathrm{M}$ Lithium chloride ( $\mathrm{LiCl}$ ) (Merck, Germany), and kept at $0{ }^{\circ} \mathrm{C}$ for $15 \mathrm{~min}$. After centrifugation $(30000 \times \mathrm{g}, 15 \mathrm{~min})$, the supernatant was dialyzed against distilled water. The S-layer protein obtained from this part, named primary $\mathrm{LiCl}$ extracted S-layer. The pellet of LiC1-extracted cells was washed twice in distilled water, resuspended in prewarmed MRS broth to an $\mathrm{OD}_{650}$ of 0.5 and incubated at $37^{\circ} \mathrm{C}$. Cells were harvested again and S-layer extraction with $\mathrm{LiCl}$ was performed and obtained S-layer protein named secondary $\mathrm{LiCl}$ extracted S-layer [16]. The total proteins from treated and untreated $\mathrm{LiCl}$ cells, also primary and secondary $\mathrm{LiCl}$ extracted S-layer were analyzed by SDS-PAGE. For further investigation, secondary structure of secondary $\mathrm{LiCl}$ extracted S-layer was analyzed by CD analysis [16].

\subsection{Secondary structure analysis of S-layer proteins by circular dichroism (CD)}

Circular dichroism is being recognized as a valuable technique for examination of secondary structure of protein in solution [17]. CD measurements were performed using Jasco J-810 spectropolarimeter (Tokyo, Japan) at room temperature. The far-UV (190-250 nm) spectra were recorded using a step size of $1 \mathrm{~nm}$ and a bandwidth of $1.5 \mathrm{~nm}$. Quartz cuvettes of $1 \mathrm{~mm}$ in path length were used. The S-layer protein concentration of $0.5 \mathrm{mg} / \mathrm{ml}$ was prepared in distilled water. The spectra were corrected for buffer contributions. The CD-spectra were analyzed and the secondary structure contents were calculated using the program Spectra Manager for Windows 95/NT, Spectra Analysis, Version 1.53.02 [Build 1], JASCO Corporation.

\subsection{Thermal analysis by differential scanning calorimetry (DSC)}

Differential scanning calorimetry or DSC is a thermoanalytical technique in which provides the information about protein thermal characterization [18]. Thermal analysis was performed with a DSC instrument (model DSC60, Shimdzu, japan). Samples of lyophilized S-layer proteins weighing 5-7 mg were encapsulated in aluminum pans and accurately weighted. An empty pan was used as reference. Samples were subjected to heating cycle between 20 and $200^{\circ} \mathrm{C}$, with a heating rate of $10^{\circ} \mathrm{C} / \mathrm{min}$.

\subsection{Dynamic light scattering (DLS) and zeta potential measurements}

To determine the monomer diameter, DLS was performed. After dialysis of the GuHCL crude extract against Tris buffer $(50 \mathrm{mM}, \mathrm{pH}$ 7) at $4{ }^{\circ} \mathrm{C}$, the supernatant containing S-layer monomeric subunits was collected by ultracentrifugation at $40000 \times \mathrm{g}$ for $30 \mathrm{~min}$ at $4{ }^{\circ} \mathrm{C}$ (two times). The supernatant was checked by DLS [19]. Dynamic light scattering measurements were taken on a Zetasizer Nano ZS (Malvern Instruments, UK). The results were expressed by percentage of population present by intensity in the sample. Zeta potential measurements of clear supernatant were also performed in a disposable Zetasizer nano cells (Malvern). The cells were washed with pure water before measurements. 


\section{Results and discussion}

\subsection{Electron microscopy}

The TEM results indicated the presence of S-layer outside the cell wall structure. As shown in Fig. 1a cell wall of L.brevis KM3 in thin electron microscopic section revealed a three layered structure with different thickness. The innermost layer, representing the plasma membrane (A), the middle layer is the peptidoglycan layer (B) and the outermost layer (C) is S-layer. An identical organization has been described in other study that the S-layer appeared as a thin layer completely covering the thick peptidoglycan layer $[10,11]$. Also, negative staining of S-layer in white extract after dialysis is displayed in the electron micrograph of Fig. 1b. This finding demonstrated during removal of the GuHCL by dialysis, the S-layer subunits reassembled spontaneously into flat sheets $[11,16]$.

\subsection{SDS-PAGE analysis}

The S-layer protein represented approximately $14 \%$ of the total protein content of the bacteria and gave a dominant band on SDS electrophoretogram [16]. Total cell proteins, S-layer protein from supernatant and pellet obtained after centrifugation of dialyzed GuHCL crude extract from two lactobacilli (L. brevis KM3 and brevis KM7) was shown in Fig. 2. Two strains were shown same dominant protein bands approximately around $48 \mathrm{kDa}$. These results are in agreement with previous studies that researchers reported molecular masses of $43-52 \mathrm{kDa}$ for S-layer proteins of different lactobacillus strains $[13,20]$. Concentration of extracted S-layer protein in total cell proteins of two strains was lower than GuHCL extractions. During dialysis, along with removal of GuHCL, S-layer proteins began to self-assembly and precipitated. So the most concentration of S-layer proteins was shown in white pellet [16].

\subsection{S-layer re-formation after first extraction with $\mathrm{LiCl}$}

One of the most interesting properties of S-layer proteins was the reformation of the S-layer proteins after first extraction and reincubation treated cells in a fresh growth medium $[11,16]$. The new S-layer material appeared during the exponential-phase on the cell surface. The extraction of S-layer proteins can be done by chaotropic denaturants such as GuHCL or by dissociating agents such as LiCl. High concentation of S-layer can be extracted by $4 \mathrm{M} \mathrm{GuHCL}$ compared with other methods as reported by Eslami et al. [15]. However, previous study has reported treatment of bacteria with $4 \mathrm{M} \mathrm{GuHCL}$ led to a severe loss of viability whereas the extraction with $5 \mathrm{M} \mathrm{LiCl}$ led to a limited loss of viability [16]. So for investigating reformation of S-layer after fisrt extraction, $\mathrm{LiCl}$ extraction was performed.

The total proteins from treated and untreated $\mathrm{LiCl}$ cells, also primary and secondary $\mathrm{LiCl}$ extracted S-layer proteins was shown in Fig. 3. As shown the same SDS-PAGE protein profile before and after $\mathrm{LiCl}$ treatment, indicating $\mathrm{LiCl}$ treated cell are able to production of S-layer protein after re-incubation in fresh growth medium. In fact, during their growth, they rebuilt a new S-layer as previously reported for S-layer proteins [11,21]. These findings are in agreement with some other authors. Frece et al. has been detected reappearance of S-layer proteins when the $\mathrm{LiCl}$ treated cells were placed in a fresh growth medium at 37 and $45^{\circ} \mathrm{C}$ [12]. Also, Lortal et al. found that during the removal of the $5 \mathrm{M} \mathrm{LiCl}$, the S-layer subunits reassembled spontaneously into sheets with the same symmetry and lattice constants as observed in vivo [16].

Also, secondary structure of secondary S-layer was measured by CD method and no significant difference in secondary structure content was measured compared with first S-layer proteins. (Table 1).

\subsection{Secondary structure analysis of SLPs by circular dichroism (CD)}

CD measurements in the far-UV region (190-250 nm) were made to investigate the amount of secondary structure of two tested S-layer proteins under various experimental conditions (Fig. 4). Also secondary structure of GuHCL extracted S-layers and $\mathrm{LiCl}$ extracted S-layers after reformation are summarized in Table 1. It is known that the CD spectrum of an $\alpha$-helix displays two negative ellipticity bands between 203 and $240 \mathrm{~nm}$, and positive ellipticity band at $193 \mathrm{~nm}$. $\beta$-sheets exhibit a broad negative band near $218 \mathrm{~nm}$ and a large positive band near $195 \mathrm{~nm}$ while disordered extended chains have a weak broad positive $\mathrm{CD}$ band near $217 \mathrm{~nm}$ and a large negative band near $200 \mathrm{~nm}$. As displayed in Fig. 4 the negative band of the protein spectrum, ranging between about 200 and $220 \mathrm{~nm}$ suggesting that $\alpha$-helices and $\beta$-sheets could be present in the S-layer proteins secondary structure. As showed in Table 1. both S-layer proteins had high content of $\beta$-sheet and low content of $\alpha$-helix structure. The content of $\beta$-sheet structure is higher than those of other Lactobacillus S-layer proteins. For example CD measurement of extracted S-layer from $L$. acidophillus, L. crispatus and L. helveticus have been showed $\beta$-sheet content of $20-40 \%[12,23]$. High $\beta$-sheet content can make surface proteins more stable. As a result, we could infer that our S-layer proteins may be stable and this must be investigated in future studies.

A comparison between secondary structure of S-layer protein of L.brevis KM3 after reformation indicate relatively similar composition of secondary structural elements compared with S-layer protein

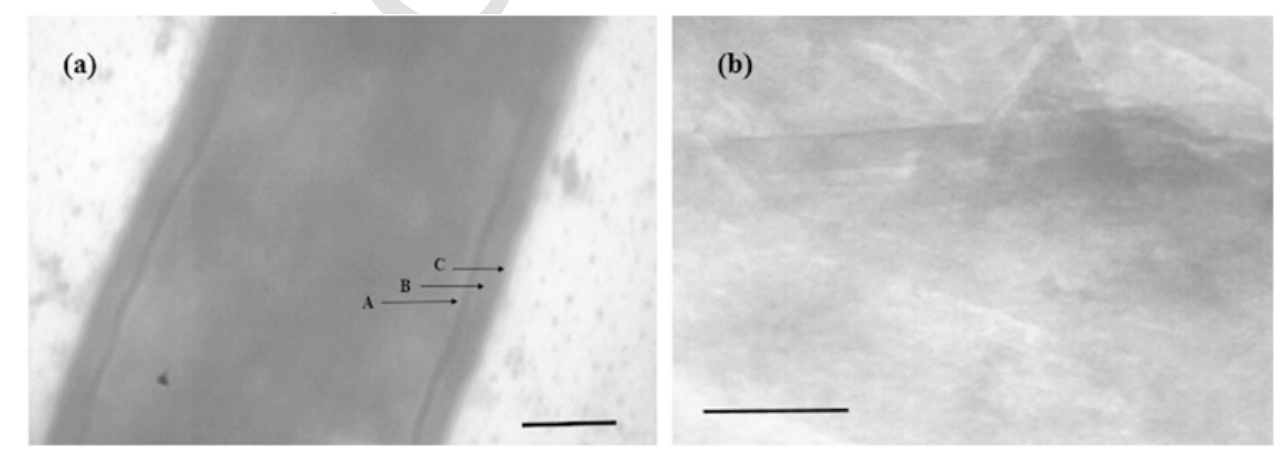

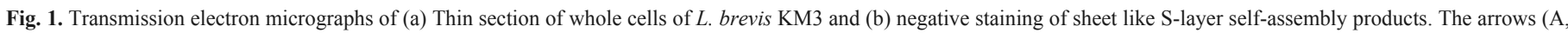
$\mathrm{B}$ and C) in panel (a) showing three-layer structure of cell wall which in layer C corresponds to the S-layer. Bars, $336 \mathrm{~nm}$. 


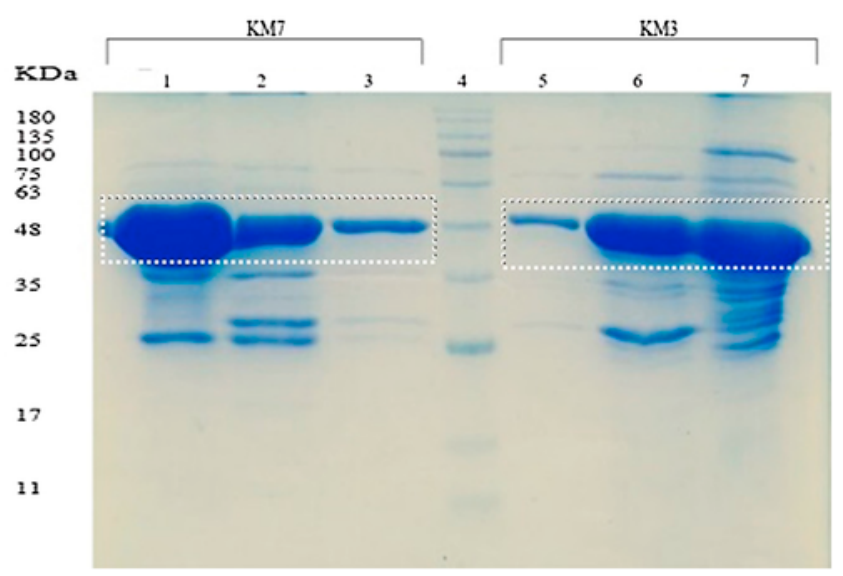

Fig. 2. SDS-PAGE analysis. Lanes $(3,5)$, Total cell protein, $(2,6)$ supernatant, $(1,7)$ pellet obtained upon centrifugation of the dialyzed GuHCL crude extract from two strains, L. brevis KM7 and brevis KM3 respectively and (4) protein marker. Marked region corresponds to the S-layer protein bands.

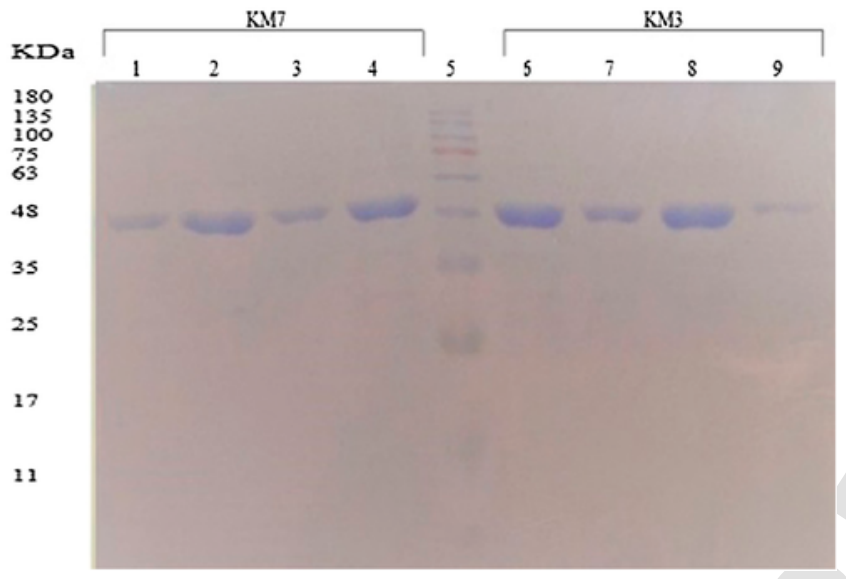

Fig. 3. SDS-PAGE analysis. Lanes $(4,6)$, Total protein from untreated cells, $(3,7)$ primary $\mathrm{LiCl}$ extracted S-layer, $(2,8)$ Total protein from treated cells, $(1,9)$ secondary $\mathrm{LiCl}$ extracted S-layer $(1,9)$ from two strains, L. brevis KM7 and brevis KM3 respectively and (5) protein marker.

Table 1

Secondary structure composition of S-layer proteins of L. brevis KM3 and L.brevis KM7.

\begin{tabular}{|c|c|c|c|c|c|}
\hline & Strains & $\begin{array}{l}\alpha \text {-helix } \\
(\%)\end{array}$ & $\begin{array}{l}\beta \text {-sheet } \\
(\%)\end{array}$ & $\begin{array}{l}\beta \text {-turn } \\
(\%)\end{array}$ & $\begin{array}{l}\text { Random coil } \\
(\%)\end{array}$ \\
\hline \multirow[t]{2}{*}{ GuHCL extracted S-layers } & KM3 & 6.8 & 42.5 & 10.2 & 40.6 \\
\hline & KM7 & 6 & 48.7 & 0 & 45.3 \\
\hline \multirow{2}{*}{$\begin{array}{l}\mathrm{LiCl} \text { extracted } \mathrm{S} \text {-layers } \\
\text { after reformation }\end{array}$} & KM3 & 8.8 & 42.8 & 11.5 & 37 \\
\hline & KM7 & 1.9 & 51.5 & 12.9 & 33.7 \\
\hline
\end{tabular}

after first extraction showing that it was not substantially altered by $\mathrm{LiCl}$ treatment. In other words, in case of this strain $\mathrm{LiCl}$ treated cell can be able reproduce S-layer protein with similar features with first extracted S-layer. But the S-layer protein of L.brevis KM7 had a limited amount of $\alpha$-helix (approximately 1.9\%) after reformation (Table 1). This conformational change may be due to S-layer reproduction or effect of $\mathrm{LiCl}$ extraction. So, this result needs further investigation.

\subsection{Thermal analysis by DSC}

Thermal behavior of lyophilized S-layer proteins has been carried out by DSC is depicted in Fig. 5. For the studied lyophilized S-layer proteins, DSC thermogram exhibited one transition peak at $67.9^{\circ} \mathrm{C}$ for L.brevis KM3 and $59.14{ }^{\circ} \mathrm{C}$ for L.brevis KM7.

Mobili et al. reported two transitions peaks for some lyophilized S-layer proteins from some L.kefir strains and L.brevis ATCC 8287 within $30-130{ }^{\circ} \mathrm{C}$ range, with maxima located at 58 and $98{ }^{\circ} \mathrm{C}$ for L.brevis ATCC 8287 and in the $67-70^{\circ} \mathrm{C}$ and $110-119^{\circ} \mathrm{C}$ for L.kefir strains [24]. Also, FTIR spectra revealed that for all the L.kefir S-layer proteins the major secondary structure modification upon heating occur closely at the first phase transitions observed by DSC. On the other hand, no relevant spectral changes were observed in first phase transition of L.brevis ATCC 8287 S-layer protein, indicating that for this strain the first phase transition only imply minor changes in the protein secondary structure. It is interesting to note that the S-layer protein of L.brevis ATCC 8287 has maximum $\beta$-sheet content (and no $\alpha$-helix content) among all S-layer proteins. Greater thermal stability of this strain correlated with the amount of $\beta$-sheet content $[25,26]$. DSC analysis of our two S-layer proteins displayed one transition peak similar to $\mathrm{T}_{\mathrm{m}}$ of first transition peaks of L.kefir strains. Secondary structure analysis of L.kefir S-layer suggesting the presence of $\alpha$-helix structures in different percentages (13-21\%) and $\beta$-sheet contents ranging from 23 to $42 \%$ [24]. Secondary structure of S-layer proteins of two lactobacillus strains as described in CD section are partly similar to L.kefir S-layer and this can be reason similarity in thermal stability of these proteins.

\subsection{Dynamic light scattering (DLS) and zeta potential measurements}

DLS was used to evaluate particularly the size and oligomerization of various particles like proteins, polymers, micelles, carbohydrates and nanoparticles [27]. In the present study, DLS was used to determine the monodispersity of monomeric S-layer proteins and determination the monomer diameter. The clear supernatant after ultracentrifugation was checked by DLS. Fig. 6 shows the average diameter distribution by percentage of the intensity of present molecules. Two population peaks were seen, but the main population of $\mathrm{S}$-layer molecules in two tested lactobacillus strains has a diameter close to $10 \mathrm{~nm}$. According to previous studies the expected diameter of monomeric S-layer protein close to 9-10 nm [19]. The results of DLS show that protein solution after ultracentrifugation (two times) was mainly composed of monomer. We must see one population peak if pure protein has been used. Therefore, characterization by DLS can be used for investigating S-layer protein purification, also stability of S-layer monomer during storage at different conditions [19,28]. Periodical DLS measurements of a sample can indicate whether the particles aggregate upon a certain time period. If particles aggregate, there will be a larger population of particles with increasing radius. Teixeira et al. demonstrated formation of protein aggregates when the protein stored for more than three weeks. However, when $10^{-3}$ M EDTA was added to the protein stock, S-layer monomer remained stable for longer periods [19].

As seen in Table 2 the zeta potentials of monomeric solution of S-layer proteins were found to be $7.39 \pm 0.66 \mathrm{mV}$ and $9.3 \pm 0.34 \mathrm{mV}$ for two Lactobacilli, L.brevis KM3 and L.brevis KM7, respectively. The isoelectric point is the $\mathrm{pH}$ of a protein solution at which the net charge or zeta potential of protein is zero. A typical characteristic of lactobacilli S-layer proteins is $\mathrm{pI}>9$.4. Therefore, solution of S-layer protein in tris buffer with $\mathrm{pH} 7$ should have positive potential. The zeta potential is a significant parameter for a number of applications 
(a)

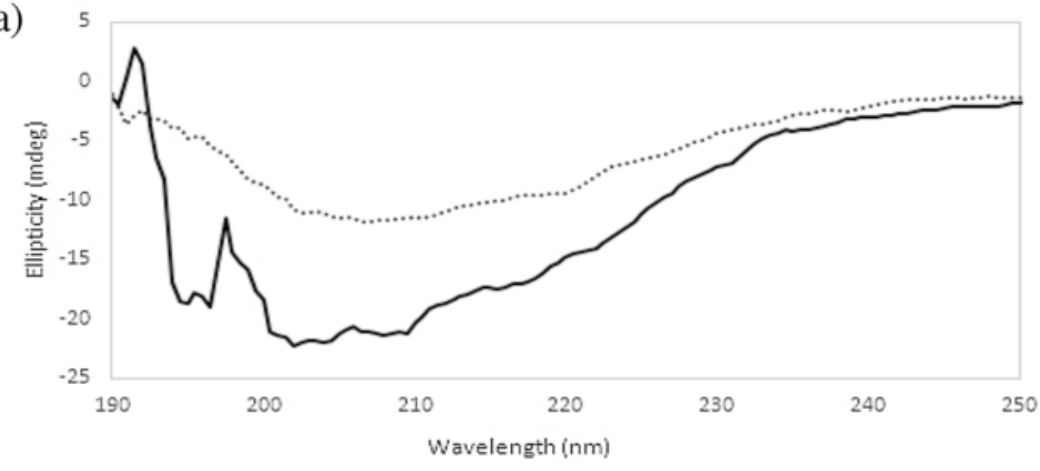

(b)

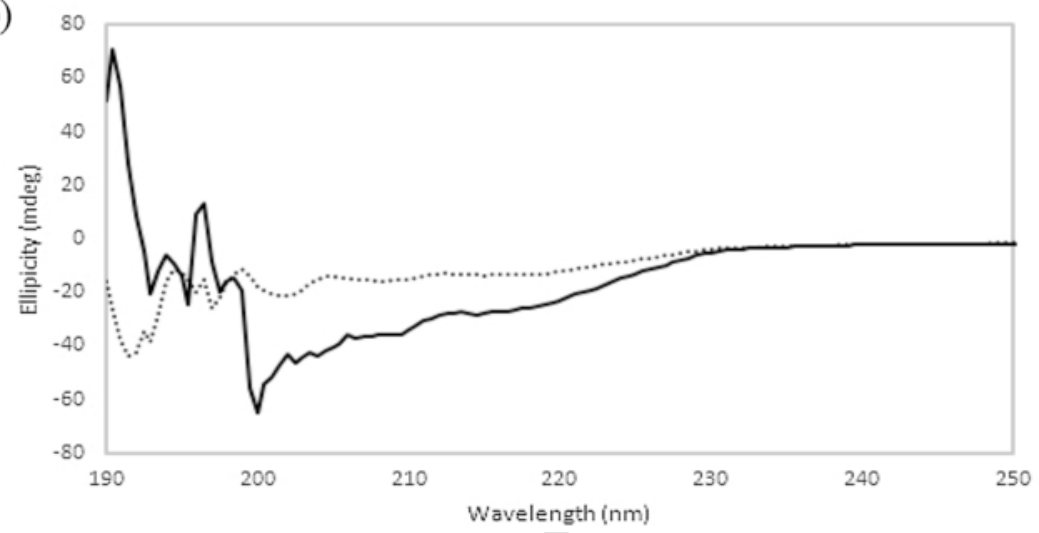

Fig. 4. The far-UV CD spectra of S-layer proteins of L. brevis KM3(a) and L. brevis KM7(b). GuHCL extracted S-layers (solid line) and LiCl extracted S-layers after reformation (dot line).

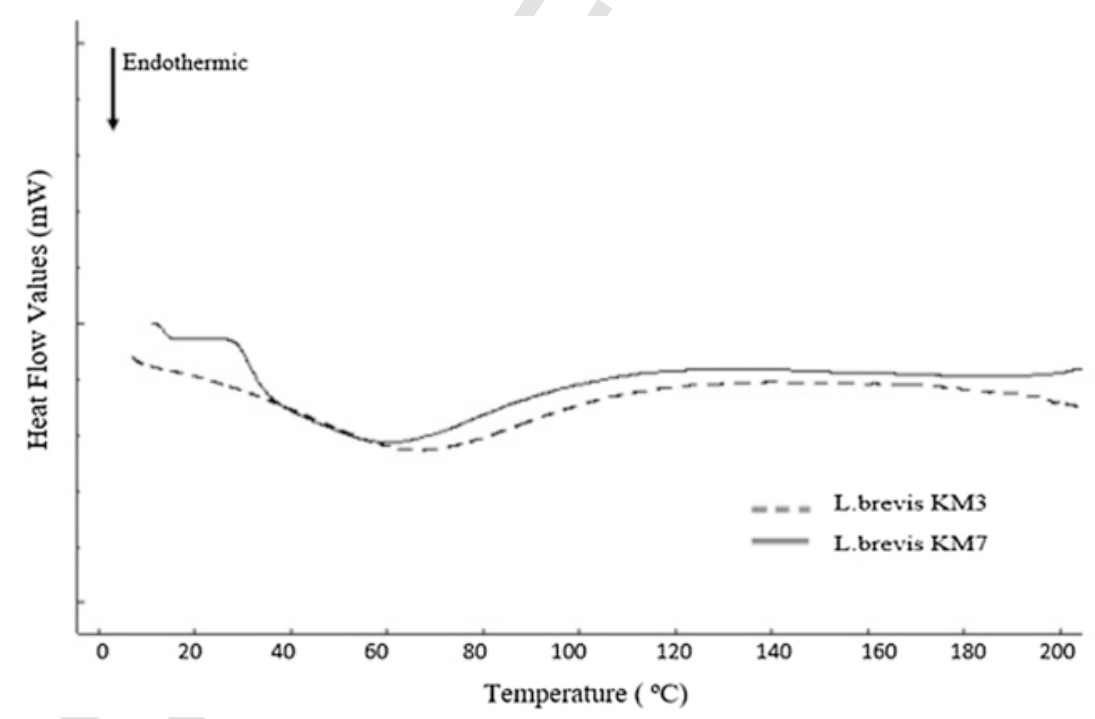

Fig. 5. DSC thermograms for lyophilized S-layer proteins from L. brevis KM3 and L. brevis KM7.

including protein separation, purification and protein stability. For example, decarboxylation of acidic amino acid in S-layer due to instability, displays negative zeta potential [29].

The zeta potential is a parameter characterizing surface charge in the presence of an aqueous solution. Functional surface groups and adsorption of ions onto surfaces can be changed zeta potential. $\mathrm{pH}$ of solution, concentration and type of salt present in the solution can be affect electrical charge of the biomolecules [29,30]. Finding the zeta potential is important for the characterization of electrochemical surface properties. 
(a)

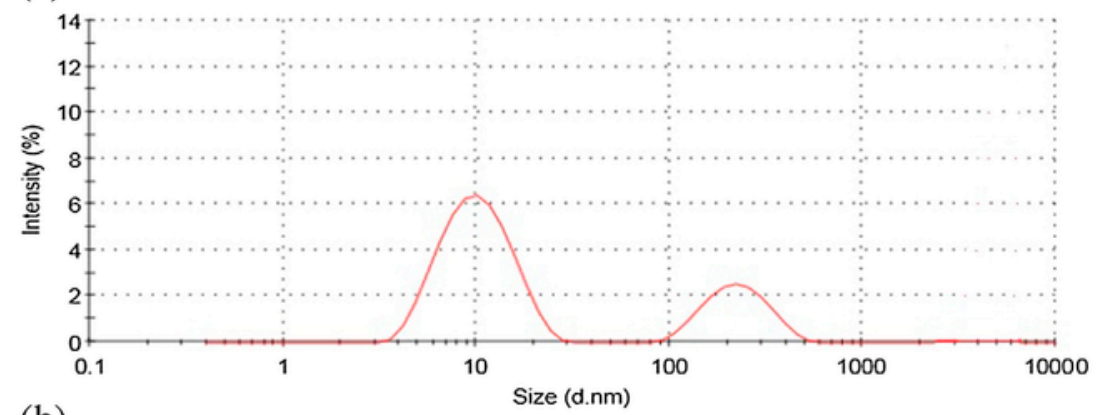

(b)

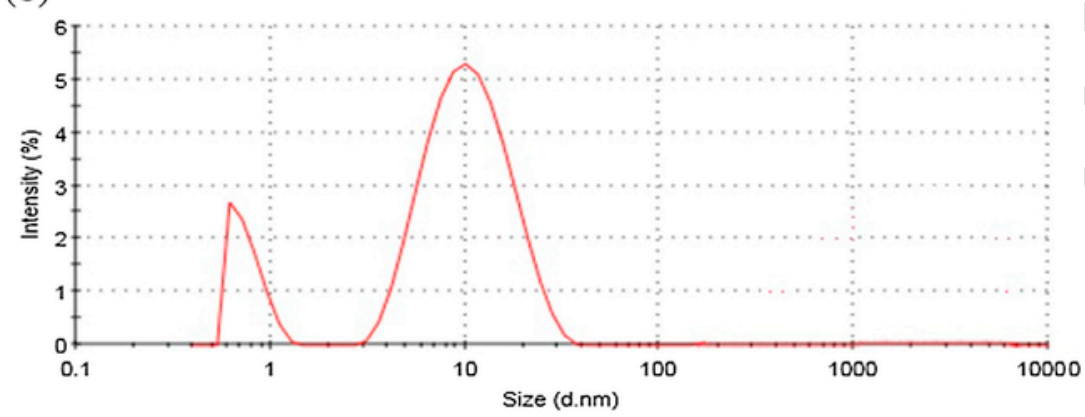

Fig. 6. Size distribution analysis of S-layer proteins of L.brevis KM3 (a) and L.brevis KM7 (b) via dynamic light scattering.

Table 2

Average zeta potential values of monomeric solution of S-layer proteins. Size precisions given by the \pm values correspond to the standard deviation of the average sizes.

\begin{tabular}{ll}
\hline & Average Zeta Potential $[\mathrm{mV}]$ \\
\hline L.brevis KM3 & $7.39 \pm 0.66$ \\
L.brevis KM7 & $9.3 \pm 0.34$ \\
\hline
\end{tabular}

\section{Conclusions}

The results obtained by TEM, clearly suggested the presence of S-layer structure outside the cell wall of L.brevis KM3. Also self-assembly of isolated S-layer proteins has been shown with negative staining. Some important biochemical properties of extracted S-layer proteins from two new and native lactobacillus strains, L. brevis KM3 and brevis KM7, were investigated. The molecular masses of extracted S-layer proteins from two strains were found to be similar. According to the far-UV CD spectra, the secondary structure of both S-layer proteins consisted mainly of $\beta$-sheet and low content of $\alpha$-helix. Thermal analysis carried by DSC method exhibited one transition peak. Monodispersity of extracted S-layer proteins were checked by DLS. The results demonstrated that the S-layer protein solutions used in this study were mainly composed of monomer. Positive zeta potential was reported for two S-layer proteins which are related to high $\mathrm{pI}$ value of lactobacillus S-layer proteins. The overall results reported here could be used as the basis for further work to identify specific structural features and kinetic of self-assembly process. Furthermore, these results could be important for the use of S-layer proteins in biotechnological applications.

\section{Uncited reference}

[22].

\section{Acknowledgments}

The authors report no conflicts of interest in this work. The authors would like to thank from the colleagues of Microbiology and Extraction-Purification Laboratories of Alzahra University, Tehran, Iran. Also, the authors thank the staff of Pharmaceutics Group in School of Pharmacy, Shahid Beheshti University of Medical Sciences, Tehran, Iran. This research did not receive any specific grant from funding agencies in the public, commercial, or not-for-profit sectors.

\section{References}

[1] E. Gerbino, P. Carasi, P. Mobili, M.A. Serradell, A. Go'mez-Zavaglia, Role of S-layer proteins in bacteria, World. J. Microbiol. Biotechnol. 31 (2015) 1877-1887.

[2] U.B. Sleytr, B. Schuster, E.M. Egelseer, D. Pum, S-layers: principles and applications, FEMS Microbiol Rev. 38 (2014) 823-864.

[3] U. Hynönen, A. Palva, Lactobacillus surface layer proteins: structure, function and applications, Appl. J. Microbiol. Biotechnol. 97 (2013) 5225-5243.

[4] B. Johnson, K. Selle, S. O'Flaherty, Y.J. Goh, T, Klaenhammer Identification of extracellular surface-layer associated proteins in Lactobacillus acidophilus NCFM, Microbiology 159 (2013) 2269-2282.

[5] J. Beganovic, J. Frece, B. Kos, A. Lebos Pavunc, K. Habjanic, J. Suskovic, Functionality of the S-layer protein from the probiotic strain Lactobacillus helveticus M92, Antonie Van Leeuwenhoek 100 (2011) 43-53.

[6] U. Hynönen, R. Kant, T. Lähteinen, T.E. Pietilä, J. Beganović, H. Smidt, K. Uroic, S. Avall-Jääskeläinen, A. Palva, Functional characterization of probiotic surface layer protein-carrying Lactobacillus amylovorus strains, BMC Microbiol. 14 (2014) 199.

[7] P. Mobili, E. Gerbino, E. Tymczyszyn, A. Zavaglia, Structural characteristics and putative role of S-layers in surface and probiotic properties of whole bacteria, Appl. Microbiol. Biotechnol. 51 (2010) 1224-1234.

[8] S. Åvall-Jääskeläinen, A. Palva, Lactobacillus surface layers and their applications, FEMS Microbiol. Rev. 29 (2005) 511-529.

[9] E. Mobarak Qamsari, R. Kasra Kermanshahi, M. Erfan, P. Ghadam, Screening of potentially probiotic lactobacillus possessing surface (S) layer protein from Iranian traditional dairy products, J. Sci. I. R. Iran (2016). in press.

[10] P. Schär-Zammaretti, M.L. Dillmann, N. D'Amico, M. Affolter, J. Ubbink, Influence of fermentation medium composition on physicochemical surface proper- 
ties of Lactobacillus acidophilus, Appl. Environ. Microbiol. 71 (12) (2005) 8165-8173.

[11] G. Garrote, L. Delfederico, R. Bibiloni, A. Abraham, P. Perez, L. Semorile, G. Antoni, Lactobacilli isolated from kefir grains: evidence of the presence of S-layer proteins, J. Dairy. Res. 71 (2004) 222-230.

[12] J. Frece, B. Kos, I.K. Svetec, Z. Zgaga, V. Mrsxa, J. Suskovic, Importance of S-layer proteins in probiotic activity of Lactobacillus acidophilus M9, J. Appl. Microbiol. 98 (2005) 285-292.

[13] J. Meng, X. Zhu, S.M. Gao, Q.X. Zhang, Z. Sun, R.R. Lu, Characterization of surface layer proteins and its role in probiotic properties of three Lactobacillus strains, Int. J. Biol. Macromol. 65 (2014) 110-114.

[14] U.K. Laemmli, Cleavage of structural proteins during the assembly of the head of bacteriophage T4, Nature 227 (5259) (1970) 680-685.

[15] N. Eslami, K.R. Kermanshahi, M. Erfan, Studying the stability of S-layer protein of Lactobacillus acidophilus ATCC 4356 in simulated gastrointestinal fluids using SDS-PAGE and circular dichroism, Iran. J. Pharm. Res. 12 (2013) 47-56.

[16] S. Lortal, J. Heienoort, K. Gruber, U.B. Sleytr, S-layer of Lactobacillus helveticus ATCC 12046: isolation, chemical characterization and re-formation after extraction with lithium chloride, J. Gen. Microbiol. 138 (1992) 611-618.

[17] S.M. Kelly, T.J. Jess, N.C. Price, How to study proteins by circular dichroism, Biochim. Biophys. Acta1751 (2005) 119-139.

[18] D. Larrea-Wachtendorff, G. Tabilo-Munizaga, L. Moreno-Osorio, R. Villalobos-Carvajal, M. Pérez-Won, Protein changes caused by high hydrostatic pressure (HHP): a study using differential scanning calorimetry (DSC) and fourier transform infrared (FTIR) spectroscopy, Food Eng. Rev. 7 (2015) 222-230.

[19] L.M. Teixeira, A. Strickland, S.S. Mark, M. Bergkvist, Y. Sierra-Sastre, C.A. Batt, Entropically driven self-Assembly of Lysinibacillus sphaericus S-layer proteins analyzed under various environmental conditions, Macromol. Biosci. 10 (2010) 147-155.

[20] J. Meng, S.M. Gao, Q.X. Zhang, R.R. Lu, Murein hydrolase activity of surface layer proteins from Lactobacillus acidophilus against Escherichia coli, Int. J. Biol. Macromol. 79 (2015) 527-532.
[21] M. Ventura, I. Jankovic, D.C. Walker, R.D. Pridmore, R. Zink, Identification and characterization of novel surface proteins in Lactobacillus johnsonii and Lactobacillus gasseri, Appl. Environ. Microbiol. 68 (2002) 6172-6181.

[22] L. Lighezan, R. Georgieva, A. Neagu, The secondary structure and the therma unfolding parameters of the S-layer protein from Lactobacillus salivarius, Eur. Biophys. J. (2016) 1-19.

[23] L. Lighezan, R. Georgieva, A. Neagu, A study of the thermal denaturation of the S-layer protein from Lactobacillus salivarius, Phys. Scripta86 (2012) 035801 .

[24] P. Mobili, A. Londero, T.M.R. Maria, M.E.S. Eusébio, G.L. De Antoni, R. Fausto, A. Gómez-Zavaglia, Characterization of S-layer proteins of Lactobacillus by FTIR spectroscopy and differential scanning calorimetry, Vib. Spectrosc. 50 (2009) 68-77.

[25] T. Yasui, K. Yoda, T. Kamiya, Analysis of S-layer proteins of Lactobacillus brevis, FEMS Microbiol. Lett. 133 (1995) 181-186.

[26] N. Iik, D. Pum, U.B. Sleytr, A. Palva, Identification and characterization of domains responsible for self-assembly and cell wall binding of the surface layer protein of Lactobacillus brevis ATCC 8287, BMC Microbiol. 8 (2008) 1-15.

[27] J. Liu, S. Falke, B. Drobot, D. Oberthuer, A. Kikhney, T. Guenther, K. Fahmy, D. Svergun, C. Betzel, J. Raff, Analysis of self-assembly of S-layer protein slp-B53 from Lysinibacillus sphaericus, Eur. Biophys. J. (2016).

[28] B. Rad, T.K. Haxton, A. Shon, S.H. Shin, H. Whitelam, C.M. Ajo-Franklin, Ion-specific control of the self-assembly dynamics of a nanostructured protein lattice, ACS Nano9 (2015) 180-190.

[29] S. Salgin, U. Salgin, S. Bahadir, Zeta potentials and isoelectric points of biomolecules: the effects of ion types and ionic strengths, Int. J. Electrochem. Sci. 7 (2012) 12404-12414.

[30] J.D. Clogston, A.K. Patri, Zeta potential measurement, Methods Mol. Biol. 697 (2011) 63-70. 